\title{
RESEARCH PROJECTS AND NETWORKS
}

The Finnish Centre of Excellence in Political Thought and Conceptual Change has launched its new website: http://www.jpu.f/polcon. It features information on the centre's diverse research activities, participants, events, and publications.

The Iberoamerican Network of Politico-Conceptual and Intellectual History has relocated its website to http://foroiberoideas.cervantesvirtual.com. Its new host has allowed it to improve its design and resources. Visit the site to access forums, articles and reviews, as well as information on events. 